\title{
RELAÇÕES ENTRE REDE URBANA E COVID-19 EM MINAS GERAIS
}

\section{RELATIONSHIP BETWEEN URBAN NETWORK AND COVID-19 IN MINAS GERAIS STATE -BRAZIL}

\author{
Wagner Batella \\ Doutor, Programa de Pós-Graduação em Geografia \\ NuGea - Núcleo de Pesquisa Geografia, Espaço e Ação \\ Universidade Federal de Juiz de Fora \\ wagner.batella@ufjf.edu.br \\ Vitor Koiti Miyazaki \\ Doutor, Programa de Pós-Graduação em Geografia do Pontal \\ Instituto de Ciências Humanas do Pontal \\ Universidade Federal de Uberlândia \\ vitor.ufu@ufu.br
}

\section{RESUMO}

O ano de 2020 marcou a primeira pandemia do século XXI causada pela COVID-19, doença transmitida pelo vírus SARS-CoV-2. Tendo surgido na cidade chinesa de Wuhan, o vírus se espalhou rapidamente para outras partes do mundo, chegando ao Brasil no final de fevereiro. Desde então, a população brasileira acompanha atônita a difusão espacial do vírus no território nacional. A entrada no país deu-se por São Paulo, maior e mais importante centro urbano do Brasil, e hoje está presente em todos os estados. Neste texto trataremos especificamente do estado de Minas Gerais, com o objetivo de analisar as relações entre a dinâmica espacial da COVID-19 e a configuração da rede urbana mineira. Para tanto, tomamos como base os dados disponibilizados pelo IBGE, bem como da Secretaria de Estado da Saúde de Minas Gerais (SES-MG). Os resultados permitem uma série de reflexões sobre a dinâmica espacial da doença, particularmente sobre seu processo de difusão, bem como sua forte relação com as interações e as concentrações espaciais de pessoas.

Palavras-chave: COVID-19. Difusão espacial. Rede urbana. Geografia da Saúde.

\begin{abstract}
The year 2020 marked the first pandemic of the 21st century caused by COVID-19, a disease transmitted by the SARS-CoV-2 virus. Having emerged in the chinese city of Wuhan, the virus spread rapidly to other parts of the world, arriving in Brazil in late February. Since then, the brazilian population has been amazed at the spatial spread of the virus in the national territory. It entered the country through São Paulo, the largest and most important urban center in Brazil, and today it is present in all states. In this text we will deal specifically with the state of Minas Gerais, with the aim of analyzing the relationship between the spatial dynamics of COVID-19 and the configuration of the urban network of the Minas Gerais state. For that, we take as a base the data made available by IBGE, as well as by the Minas Gerais State Department of Health (SES-MG). The results allow a series of reflections on the spatial dynamics of the disease, particularly on its diffusion process, as well as its strong relationship with interactions and spatial concentrations of people.
\end{abstract}

Keywords: COVID-19. Spatial diffusion. Urban network. Geography of Health.

\section{INTRODUÇÃO}

O ano de 2020 marcou a primeira pandemia do século XXI causada pela COVID-19, doença transmitida pelo vírus SARS-CoV-2. Tendo surgido na cidade chinesa de Wuhan, o vírus se espalhou rapidamente para outras partes do mundo, chegando ao Brasil no final de fevereiro, segundo dados oficiais do Ministério da Saúde. Desde então, a população brasileira acompanha atônita a difusão

Recebido em: 10/05/2020

Aceito para publicação em: 21/05/2020. 
espacial do vírus no território nacional. A entrada no país deu-se por São Paulo, maior e mais importante centro urbano do Brasil, e hoje está presente em todos os estados.

Em Minas Gerais, estado com maior número de cidades do país, a COVID-19 apresenta uma dinâmica espacial estreitamente correlata à rede urbana deste estado. Tal configuração permite uma série de reflexões sobre a dinâmica espacial da doença, particularmente sobre seu processo de difusão, bem como sua forte relação com as interações e as concentrações espaciais de pessoas.

O presente trabalho visa analisar a distribuição espacial dos casos confirmados dessa doença entre as cidades de MG até a data de 05 de maio de 2020, bem como discutir as relações dessa configuração espacial com a rede urbana mineira. Para tal, o texto segue estruturado em três partes, sendo a primeira voltada para uma discussão acerca das relações entre saúde e cidades. $\mathrm{Na}$ segunda seção, a rede urbana mineira é apresentada e problematizada. Por fim, a terceira parte do trabalho explora a distribuição espacial da COVID-19 em Minas Gerais, bem como tece um arrazoado acerca de elementos para compreensão da distribuição espacial dessa doença.

\title{
SAÚDE E ESPAÇO URBANO
}

Analisando os aportes do médico John Snow para o desenvolvimento da Epidemiologia em meados do século XIX, o jornalista científico Steven Johnson (2008) destacou, como principais feitos do médico londrino, as suas contribuições para o desenvolvimento da saúde pública e do urbanismo. Parte da cidade de Londres foi assolada por um surto de cólera em 1854. Mas, foi por meio da ciência, sobretudo da análise espacial, que Snow refutou o paradigma dominante à época para explicação da difusão de doenças, a teoria do miasma, que apontava o ar sujo e contaminado como o grande transmissor de doenças que recorrentemente apareciam naquela cidade. $O$ fato é conhecido e muito estudado na perspectiva da saúde, mas também por ter transformado o futuro das cidades, sobretudo por meio do saneamento:

\begin{abstract}
Estabelecer sistemas de abastecimento de água potável e de remoção de dejetos tornou-se o mais importante projeto de infraestrutura de toda cidade industrializada do planeta. A aparência da rede elétrica, em torno da virada do século, tende a atrair mais atenção, mas foi a construção da invisível rede de esgoto e encanamentos de água potável que tornou a cidade moderna mais segura para os intermináveis prazeres de consumo que a eletricidade proporcionaria (JOHNSON, 2008, p. 194)
\end{abstract}

É fato que tais transformações tornaram as cidades mais seguras mundo afora, fruto de conquistas urbanas com foco na redução e combate de doenças. Apesar disso, a história tem sido marcada pelo surgimento de diversas doenças infecciosas que encontram nas cidades as condições propícias para sua difusão, principalmente com a intensificação do processo de urbanização e aumento da população urbana.

Essas ameaças epidemiológicas muitas vezes resultam do contato constante entre pessoas, animais, mercadorias etc., evidenciando a importância do estudo das condições de saúde e saneamento nas cidades, mas também da incorporação de escalas mais amplas de análise para a discussão espacial sobre as doenças, qual seja, a perspectiva interurbana, pensada aqui na dimensão das redes urbanas. Em um mundo em que a circulação ganha relevância e os fluxos se tornam mais intensos, extensos e seletivos (SANTOS E SILVEIRA, 2006), o olhar para a escala da rede urbana é fundamental.

Sobre este aspecto, inclusive se referindo ao contexto da pandemia no qual nos encontramos, Pereira (2020 p.2), ao tomar como base as ideias de Milton Santos, reforça a importância dos fluxos no período contemporâneo, quando a circulação se torna cada vez maior e as redes passam a representar o "modo de vida urbano-regional-internacional do qual usufruímos para comprar, viajar, vender, produzir e comunicar". Ainda para o autor, considerando-se esse contexto de ampliação da circulação, "certamente, na contemporaneidade o sentido etimológico da palavra pandemia ganha, de fato, condições empíricas de realização". Sendo assim, as relações interurbanas e a circulação no âmbito das redes ganham relevância na perspectiva da sociedade, inclusive em relação a questões que envolvem a saúde pública.

Há uma vasta bibliografia com foco na difusão espacial de doenças e sua relação com a rede urbana. Pyle (1960 apud CATÃO, 2016), por exemplo, interpretou a difusão de epidemias de cólera durante o século XIX nos Estados Unidos. Dentre os resultados apresentados, a posição que a cidade apresentava na rede urbana foi um dos elementos significativos para a compreensão do padrão espacial de contaminação. 
Focando a realidade brasileira, particularmente o estado de São Paulo, Catão (2016) estudou o complexo patogênico do dengue. Segundo o autor, há forte correlação espacial entre a intensidade de casos do dengue e as cidades com maior centralidade no estado de São Paulo.

Por sua vez, em estudo recente e pensando a realidade do Pará, Souza e Ferreira Júnior (2020) analisaram a difusão da COVID-19 naquele estado, evidenciando que a trajetória da enfermidade seguiu a hierarquia da rede urbana durante seu caminho de contaminação no primeiro mês da doença.

Ainda no âmbito da atual pandemia, diversos outros trabalhos têm se debruçado em estudos que contemplam a rede urbana. O trabalho de Pereira (2020), por exemplo, estabelece relações entre o nível de centralidade das cidades francesas e a distribuição dos casos da COVID-19. Silva e Muniz (2020) também destacam a difusão da COVID-19 no território cearense para além da capital e de sua região metropolitana, num processo de interiorização incluindo cidades importantes da rede.

Esses estudos corroboram um padrão de difusão espacial que é conhecido como difusão hierárquica, ou seja, o fenômeno difundido segue um padrão conduzido pela lógica da ordem ou hierarquia da rede (CATÃO, 2016). Tais estudos evidenciam a importância da rede urbana na análise espacial da difusão de doenças.

Soma-se a isso o fato de que a oferta de serviços de saúde, por exemplo, também apresenta forte relação com a hierarquia dos centros urbanos no âmbito da rede, variando de acordo com o grau de complexidade e tipos de serviços, conforme demonstrado por estudos realizados pelo Instituto Brasileiro de Geografia e Estatística - IBGE (2008 e 2020). Ao mesmo tempo, há um conjunto de fatores que torna essa relação mais complexa, sobretudo diante das diferenças em relação às condições econômicas, como apontaram Simões et al. (2004), ao diagnosticarem desigualdades espaciais na oferta de serviços de saúde em Minas Gerais.

A relação entre oferta de serviços de saúde, cidades e epidemias se reveste da maior importância no período contemporâneo em função das transformações no modo de vida urbano observadas sobretudo durante o último quartel do século XX. Sposito e Guimarães (2020), no contexto da atual pandemia causada pelo vírus SARS-CoV-2, causador da COVID-19, chamaram atenção, já no primeiro mês das contaminações no Brasil, para o fato de que o modelo de difusão desta doença se relaciona com as interações espaciais na rede urbana. Diante disso, segundo os autores, os recursos metodológicos para análise da dinâmica espacial desta nova doença precisam ser alterados, pois a complexidade do mundo hodierno nos coloca novos desafios. Tais desafios podem ser sintetizados, ainda segundo os autores, nos seguintes pontos: a) as escalas das relações, da economia e da vida foram ampliadas, modificando também seus intercruzamentos; b) hoje temos um quadro no qual mais pessoas moram concentradas na cidade em detrimento do campo; c) vivemos numa sociedade urbana guiada para o consumo; d) a mobilidade espacial hoje é muito maior do que em outras épocas, quando também experimentou-se os impactos de outras pandemias; e) em função da maior mobilidade, consome-se mais bens, mercadorias, serviços e espaços; f) dependemos menos das relações familiares e avançamos escalas sucessivas, rompendo com os círculos da casa e alcançando a cidade e o mundo. Esses tópicos não visam resumir as ideias dos autores, mas sim apresentar elementos que nos permitam a concordar com eles no argumento de que "o Vírus da Covid-19 tem mais condições de se distribuir espacialmente hoje do que teria um século atrás" (SPOSITO; GUIMARÃES, 2020, p.2).

Como a proposta empírica deste trabalho visa analisar o padrão de distribuição espacial da Doença do Coronavírus em Minas Gerais, segue-se com uma discussão da rede urbana deste estado.

\section{SOBRE A REDE URBANA MINEIRA}

Minas Gerais se constitui em uma unidade da federação de grande extensão territorial, além de possuir o maior número de municípios entre os estados brasileiros. Cabe ressaltar ainda que se trata do segundo estado mais populoso do país, com aproximadamente 20 milhões de habitantes. Sendo assim, o estado apresenta grande quantidade de centros urbanos, de diferentes portes demográficos e que desempenham papéis variados no âmbito da rede de cidades, num contexto marcado pela diversidade e complexidade do cenário urbano-regional.

Se consideramos o último estudo realizado pelo Instituto Brasileiro de Geografia e Estatística - IBGE em relação à rede urbana, denominado Regiões de Influência das Cidades - REGIC (IBGE, 2008), essas diversidade e complexidade se fazem bastante presentes e representadas. Tal estudo constitui-se em uma pesquisa que leva em consideração a hierarquia e a área de influência dos 
centros, considerando-se a oferta de bens e serviços e a intensidade das ligações entre as cidades, fundamentais, por exemplo, para o planejamento e políticas públicas diversas. O resultado final do REGIC considerou a classificação hierárquica dos centros urbanos, contemplando cinco grandes níveis (metrópoles, capitais regionais, centros sub-regionais, centros de zona e centros locais).

Para o caso mineiro, por exemplo, a REGIC permite observar que, além da forte centralidade desempenhada por Belo Horizonte (classificada pelo estudo como metrópole), o estado possui diversas outras centralidades, tais como capitais regionais e centros sub-regionais. Além disso, alguns centros e regiões do estado fazem parte da área de influência de outras metrópoles além de Belo Horizonte.

Ao mesmo tempo que tais aspectos demonstram a complexidade que envolve as relações entre hierarquia urbana e áreas de influência em Minas Gerais, reforçam também o fato de que as redes de cidades e, consequentemente, as diferentes interações espaciais não se restringem aos limites político-administrativos. Portanto, esta "rede urbana mineira" não se limita apenas ao estado de Minas Gerais, uma vez que está integrada e faz parte da ampla rede de centros urbanos brasileiros e, dessa maneira, apresenta uma combinação complexa de relações. O próprio estudo do IBGE (2008) demonstra tal aspecto, assim como Corrêa (2000) quando, ao relacionar rede urbana e formação espacial, reforça que interações complexas incluem determinações gestadas em diversas escalas. $\mathrm{Na}$ realidade, frente ao desenvolvimento das técnicas e transportes e telecomunicações, a sociedade contemporânea está cada vez mais interligada e conectada por meio de interações diversas e complexas, tal como já ressaltado por Castells (1999).

De qualquer forma, a hierarquia dos centros e suas respectivas áreas de influência, reveladas por exemplo pelo REGIC, continuam fundamentais para a compreensão de várias dinâmicas e processos que configuram a rede urbana.

Para ilustrarmos, portanto, este contexto das interações entre os centros urbanos com um olhar para Minas Gerais, recorremos aos dados do IBGE (2008). Do ponto de vista da hierarquia urbana, observa-se na figura 1 a localização dos diferentes níveis de centralidade urbana no território mineiro.

Figura 1 - Minas Gerais: hierarquia e ligações dos centros urbanos, 2007

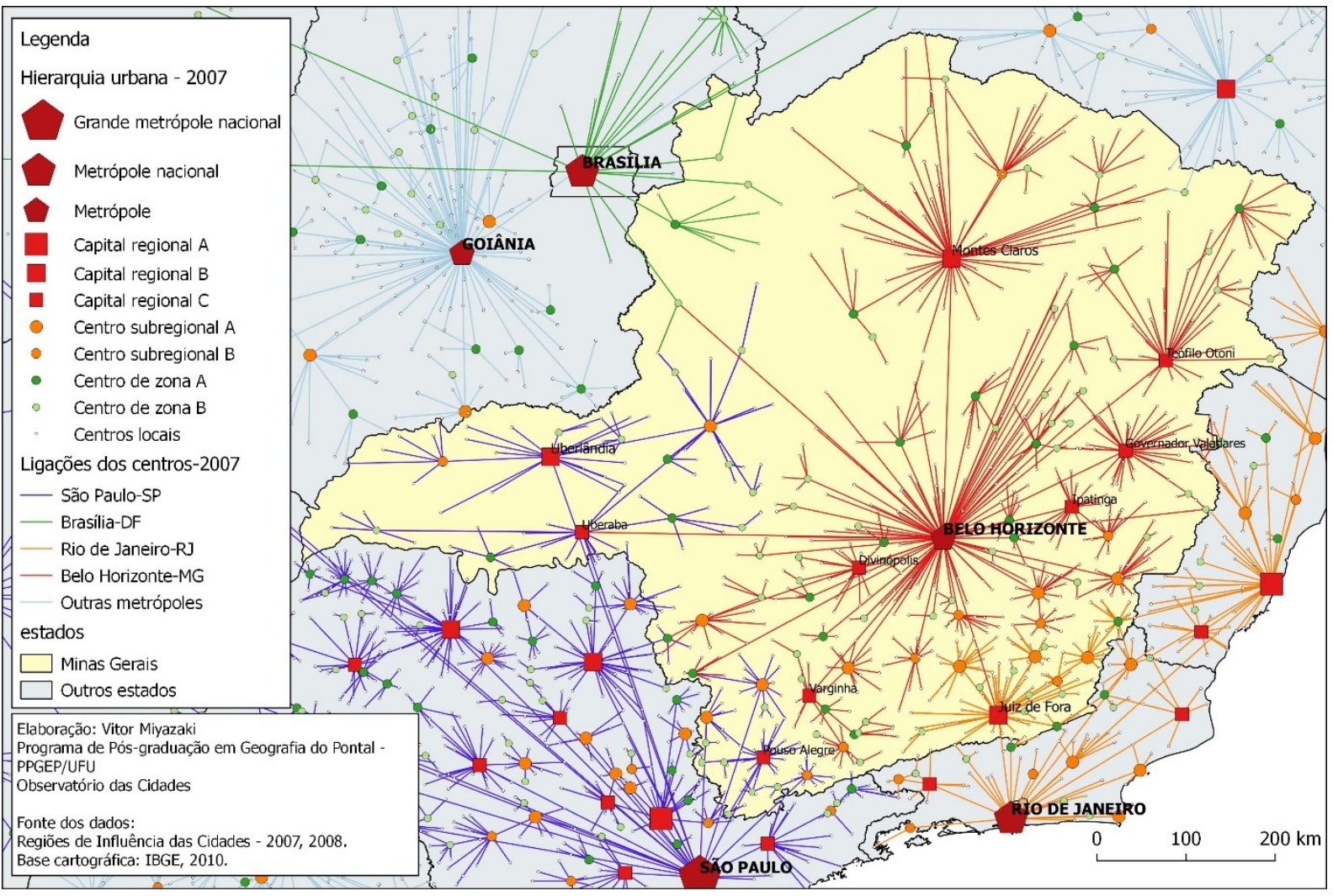

Fonte: Elaboração dos autores 
Para além da metrópole mineira, cabe destacar a presença significativa de vários centros que desempenham papéis regionais relevantes, como nos casos das capitais regionais, centros subregionais e centros de zona. Sobre este aspecto, Amorim Filho, Rigotti e Campos (2007) demostraram muito bem a quantidade e diversidade de cidades médias, por meio de uma proposta de classificação para vários centros urbanos.

Grande parte destes centros estão articulados a Belo Horizonte, que se estabelece no topo desta hierarquia no contexto mineiro desempenhando papel de Metrópole. Ao mesmo tempo, como mencionado anteriormente, outros centros estão integrados somente a outras metrópoles ou, em alguns casos, compartilham a área de influência com Belo Horizonte. Isto também fica evidente na figura 1, ao se observar as ligações entre os centros, por exemplo, a influência da metrópole paulista no Triângulo Mineiro e Sul de Minas, do Rio de Janeiro na Zona da Mata Mineira e de Brasília no Noroeste do estado.

Estas características já foram reforçadas por Guimarães e Faria (2006), quando, ao proporem uma regionalização para o estado de Minas Gerais, delimitaram quatro áreas de influência metropolitana no território mineiro, polarizadas por Belo Horizonte, São Paulo, Rio de Janeiro e Brasília.

Esta conformação é reforçada pela infraestrutura e fluxos rodoviários que integram e articulam esta rede de cidades e áreas de influência. Minas Gerais possui a maior malha rodoviária federal do país e conta com "corredores" rodoviários com denso fluxo de tráfego que interligam centros importantes do estado e do Brasil.

Estes aspectos demonstram o quão complexo é a compreensão de dinâmicas atinentes às interações espaciais no território mineiro, lançando desafios para o planejamento regional, a elaboração de políticas públicas, assim como, por exemplo, para a leitura e análise da difusão de pandemias, como é o caso do cenário vivenciado na atualidade. Trata-se, neste caso, de um desafio que envolve um problema de saúde pública.

Como já destacado por Sposito e Guimarães (2020), a circulação de pessoas tem peso na difusão de pandemias, sobretudo numa sociedade cada vez mais urbana e com maior mobilidade espacial. Ainda para estes autores, o movimento de difusão do vírus "ocorre, em grande medida, segundo a estrutura da rede urbana e consoante sua hierarquia urbana” (SPOSITO e GUIMARÃES, 2020, p.3).

Ao que indicam os dados oficiais, em Minas Gerais há relações importantes entre a rede urbana, sobretudo no que se refere à hierarquia e os níveis de centralidade, com a espacialização dos casos da COVID-19. No estado, o primeiro caso registrado de COVID-19 ocorreu no município de Divinópolis, localizado na porção centro-oeste de MG, na data de 08 de março de 2020. Quase dois meses depois, no dia 05 de maio, o número total registrado no estado chega ao montante de 2.452 casos, distribuídos entre 196 municípios.

\section{ANÁLISE ESPACIAL DA COVID-19 EM MINAS GERAIS}

A difusão da COVID-19 no Brasil se inicia por meio das metrópoles, ou seja, a partir do topo da hierarquia urbana, considerando-se as suas possibilidades de ligações e articulações em nível internacional. Tanto que os primeiros casos confirmados no país foram registrados em São Paulo e, posteriormente, em outras metrópoles, como Rio de Janeiro, Fortaleza e Brasília. Assim, a partir destes centros, a difusão ocorreu pelo território brasileiro, muitas vezes com fortes relações com a rede urbana. Catão (2016), ao citar Haggett (1979), lembra que esse tipo de difusão ocorre de forma centrífuga. Para o autor,

A difusão hierárquica ocorre dentro de uma lógica de "ordem, classe ou hierarquia" (HAGGETT, 1979, p. 299) em que o item ou fenômeno difundido obedece a uma rede hierárquica e possui um sentido, como uma inovação na rede urbana clássica. Muitas vezes ela pode se dar em saltos como já havia notado Hägerstrand (1968)" (CATÃO, 2016, p.17).

Embora se destaque o peso da hierarquia no processo de difusão, menciona-se também outros tipos de relacionamento, como a possibilidade de saltos escalares em algumas situações. Isto porque, como já destacado anteriormente, a intensificação dos fluxos e o peso da circulação a partir do desenvolvimento das técnicas, sobretudo de transporte e comunicação, tornam o cenário mais complexo e que muitas vezes supera as relações hierárquicas.

De qualquer forma, os dados sobre os casos de COVID-19 levantados apontam que há um peso importante da hierarquia urbana, inclusive ao se observar as ocorrências em Minas Gerais. A figura 2 
mostra a configuração espacial dos casos de COVID-19 confirmados neste estado até o dia 05 de maio de 2020. É possível observar uma maior concentração na capital, Belo Horizonte, seguida de alguns polos regionais distribuídos no território estadual. Ainda sobre esta configuração, considerando os eixos rodoviários, é possível destacar três aglomerações lineares, sendo a primeira ao longo da BR-381, no Sul de Minas, no eixo entre São Paulo e Belo Horizonte; a segunda encontrase na mesma rodovia, mas em seu prolongamento de Belo Horizonte até o Vale do Aço; e a terceira, ao longo da BR-040, entre Rio de Janeiro e Belo Horizonte, na Zona da Mata mineira. Caberia ainda ressaltar que a expressiva quantidade de casos em Uberaba e Uberlândia também pode estar relacionada à possível conformação de um eixo, atrelado à BR-050, que corta o Triângulo Mineiro e se constitui em importante via de ligação rodoviária entre São Paulo e Goiânia/Brasília.

Figura 2 - Número de casos confirmados de COVID-19 nos municípios do estado de Minas Gerais até o dia 05 de maio de 2020

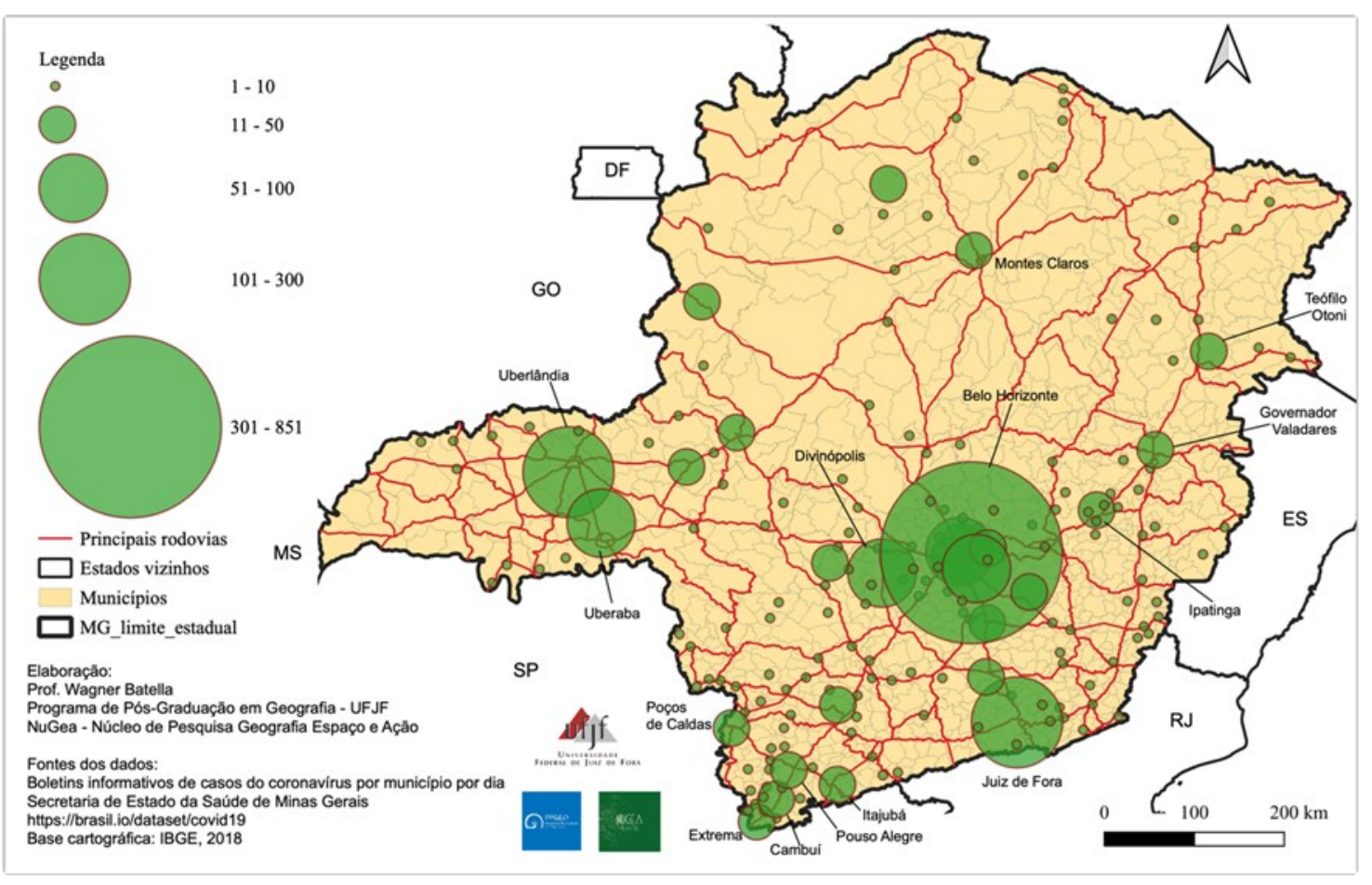

Fonte: Elaboração dos autores

Em uma comparação com a figura 1, é possível notar uma sobreposição entre a ocorrência espacial desta enfermidade, sua intensidade e a hierarquia urbana. A cidade de Belo Horizonte é classificada como uma metrópole, segundo o IBGE (2008), sendo o principal centro da rede urbana mineira. O município de Belo Horizonte apresentou o maior número de casos (851), o que corresponde a $34,28 \%$ do total em MG. A Região Metropolitana de Belo Horizonte - RMBH possui população estimada em 2019, segundo o IBGE, de aproximadamente seis milhões de habitantes, sendo 2.512.070 somente no município de Belo Horizonte, conformando, dessa maneira, a maior aglomeração urbana do estado e também a maior concentração de casos oficiais da doença em tela. Isto porque a maior centralidade no âmbito da rede urbana, resultante da maior e mais diversa oferta de bens e serviços, impacta na circulação de pessoas e, consequentemente, na difusão de doenças, como é o caso da COVID-19. Neste ponto, reforçamos o que Pereira $(2020$, p.8) menciona, ao analisar a distribuição dos casos da COVID-19 na França:

Aparenta-nos que a disseminação do caso, malgrado exceções, é mais intensa nas centralidades das redes urbanas. Mas, por quê? É a diversidade e intensidade dos fluxos e trocas com o exterior o fator decisivo para o estabelecimento inicial da epidemia. Em seguida, a própria aglomeração populacional contribui. 
Na sequência, observa-se uma segunda classe representada no mapa da figura 2 com intervalo de 101 a 300 casos. Nessa classe encontram-se duas cidades, Juiz de Fora e Uberlândia que possuem, respectivamente, populações totais estimadas para 2019 de 568.873 e 691.305 habitantes. A primeira contabilizava 223 casos, $9 \%$ do total do estado, enquanto a segunda registrou 142 casos, $6 \%$ do montante mineiro. No estudo de Amorim Filho, Rigotti e Campos (2007), essas cidades foram as únicas de Minas Gerais classificadas como grandes centros regionais. Segundo esses autores:

\begin{abstract}
Esses grandes centros regionais possuem um forte contingente populacional: no caso de Minas Gerais, uma população urbana em torno de 400.000 habitantes. (...) Polarizam vastos espaços regionais e mantêm relações econômicas, culturais e demográficas até mesmo com cidades e regiões situadas fora de Minas Gerais. (AMORIM FILHO; RIGOTTI; CAMPOS, 2007, p.9).
\end{abstract}

Segundo tal classificação, essas são cidades que possuem um peso expressivo na rede urbana mineira em função de seu porte demográfico, mas também pelo seu dinamismo econômico e de infraestrutura. Elas polarizam duas importantes regiões mineiras, a Zona da Mata, no caso de Juiz de Fora, e o Triângulo Mineiro no caso de Uberlândia, e possuem trocas intensas com regiões de outros estados, respectivamente Rio de Janeiro e São Paulo.

Diante disso, além da centralidade urbana e do grande contingente demográfico, a situação geográfica destes dois centros também pode ter contribuído para o expressivo número de casos, uma vez que ambos mantêm relações com duas outras metrópoles importantes do país: São Paulo, no caso de Uberlândia, e Rio de Janeiro, em Juiz de Fora. Cabe ressaltar que estas duas metrópoles apresentam grande número de casos de COVID-19, sendo São Paulo o epicentro da pandemia no país.

Há uma terceira classe, representada na figura 2 com intervalo entre 51 e 100 casos, na qual se encontram quatro municípios: Nova Lima e Contagem, que integram a RMBH, Divinópolis, na porção centro-oeste do estado, e Uberaba, no Triângulo Mineiro. Juntas, essas cidades representam 12\% dos casos registrados em Minas Gerais. Os quatro municípios se inserem na rede urbana mineira de forma distinta e, para análise de seus papéis na rede, bem como a correlação com os casos de COVID-19 nelas registradas, suas posições geográficas devem ser consideradas.

Contagem e Nova Lima devem ser interpretadas, juntamente com outras cidades, nas dinâmicas da Região Metropolitana que integram. Nessas regiões, as interações, as trocas e os movimentos são mais intensos, da mesma maneira que a concentração de uma infraestrutura voltada para a saúde. Uberaba é um importante polo regional, mas numa condição de relativa proximidade com outro polo, Uberlândia. As quatro cidades dessa terceira classe (figura 2), juntamente com a RMBH e Uberlândia, formam dois grandes clusters no estado. Sendo um na região do Triângulo Mineiro e outro na parte central.

Uma quarta classe, com intervalo de 11 a 50 casos, aglutina 23 municípios com posições diversas na rede urbana mineira. A maior parte dessas cidades são importantes polos regionais do estado de Minas Gerais, como Montes Claros, Teófilo Otoni, Governador Valadares, Barbacena, Ipatinga, Paracatu, Varginha, Conselheiro Lafaiete, Patos de Minas, Itajubá e Pouso Alegre. Além da forte centralidade que convergem para elas vindas de outros municípios que integram suas respectivas regiões, tais cidades concentram importantes equipamentos de infraestrutura como estabelecimentos comerciais, hospitais, escolas e universidades etc. que reforçam a atração de pessoas. Além disso, esses polos regionais apresentam complexa infraestrutura que influencia na circulação de pessoas como aeroportos, rodovias, hidrovias etc.

Evidentemente que o número de casos em cada um dos municípios deste grupo varia de acordo com a situação geográfica e as especificidades regionais. A título de exemplo, do ponto de vista do nível de centralidade, é possível destacar, por exemplo, Varginha, Governador Valadares e Teófilo Otoni, que se constituem em capitais regionais. Em relação às ligações entre os centros, poderíamos destacar situações como o de Paracatu e sua conexão com Brasília, Poços de Caldas e Pouso Alegre no âmbito da área de influência de São Paulo, entre outros casos.

Duas cidades deste grupo pertencem à RMBH, Betim e Sabará, e há um grupo de outras cidades menores. Neste último, destacam-se as cidades de Extrema e Cambuí. Embora sejam municípios com populações menores que 30.000 habitantes, apresentam respectivamente 42 e 15 casos registrados, ou seja, 2,3\% do total de casos dos 853 municípios mineiros. Este percentual pode parecer pouco expressivo, mas reforça-se o fato de que essas cidades integram a mesma classe de outras que são polos regionais ou fazem parte da RMBH. O destaque para estas cidades se deve 
menos pelos papéis que desempenham na rede urbana e mais pela posição geográfica de relativa proximidade com São Paulo, epicentro da pandemia no Brasil, o que nos leva a reforçar o fato de que, embora a hierarquia seja relevante para análise da difusão e análise da ocorrência desta pandemia, ela não deve ser entendida de maneira rígida e definitiva. Se por um lado, o período atual da globalização é marcado pelas interações que ocorrem em saltos escalares, subvertendo a hierarquia, interpretações clássicas pautadas pelas relações de proximidade ainda importam, sobretudo na análise de processos como a difusão de doenças.

\section{CONSIDERAÇÕES FINAIS}

O atual cenário de pandemia tem gerado uma série de impactos na sociedade brasileira e, ao mesmo tempo, tem lançado desafios no sentido de se buscar e propor ações que diminuam a difusão do vírus SARS-CoV-2 pelo território. Para tanto, o papel da ciência, por meio de suas mais diversas áreas, é fundamental neste processo.

Historicamente a Geografia tem desempenhado um importante papel nesses estudos, seja por meio de abordagens com foco na cartografia e análise espacial, seja na compreensão acerca das relações entre doenças e produção do espaço, considerando suas caraterísticas físicas, sociais, subjetivas e temporais. Fato é que os impactos da difusão do vírus agravam as desigualdades sociais e regionais em um país já marcado por profundas fragmentações, como o Brasil.

No caso dos dados analisados neste texto, fica evidente as relações existentes entre o número de casos de COVID-19 e a rede urbana, com destaque para o nível de centralidade e as ligações entre os centros, incluindo, por exemplo, a infraestrutura de circulação. No entanto, como se viu, a hierarquia é uma dimensão clássica e relevante em estudos sobre redes urbanas. Apesar disso, é fato que as doenças, bem como outros fenômenos espaciais estudados na escala das redes urbanas, não se restringem à rigidez da hierarquia. Faz-se importante repetir que, assim como o período atual da globalização é marcado pelas interações que ocorrem em saltos escalares, subvertendo a hierarquia, interpretações clássicas pautadas pelas relações de proximidade ainda importam, sobretudo na análise de processos como a difusão de doenças.

Diante disso, a partir deste diagnóstico inicial, procuraremos incorporar novas análises a respeito da situação da COVID-19 no estado de Minas Gerais, por meio de uma agenda de pesquisa que levará em consideração novos aspectos a serem analisados. Propomos, inicialmente, um levantamento e espacialização de equipamentos e infraestrutura de atendimento à saúde em Minas Gerais por município. Além disso, pretendemos estabelecer uma análise da difusão espacial da COVID-19 no território mineiro, considerando-se as datas de notificação de pessoas infectadas, bem como os casos suspeitos e óbitos relacionados ao vírus.

\section{REFERÊNCIAS}

AMORIM FILHO, O. B.; RIGOTTI, J. I. R.; CAMPOS, J. Os níveis hierárquicos das cidades médias de Minas Gerais. RA'EGA, Curitiba: UFPR, n.13, p.7-18, 2007. https://doi.org/10.5380/raega.v13i0.7784

CASTELLS, Manuel. A sociedade em rede. 2. ed. São Paulo: Paz e Terra, 1999.

CATÃO, R. C. Expansão e consolidação do complexo patogênico do dengue no Estado de São Paulo: difusão espacial e barreiras geográficas. 2016. 274f. Tese (Doutorado em Geografia) Faculdade de Ciências e Tecnologia, Universidade Estadual Paulista, Presidente Prudente.

CORREAA, R. L. Rede urbana e formação espacial - uma reflexão considerando o Brasil. Território, UFRJ: Rio de Janeiro, n.8, p.121-129, 2000.

GUIMARÃES, E. N.; FARIA, G. A. Integração e desenvolvimento regional: uma proposta de regionalização de Minas Gerais. In: SEMINÁRIO DE ECONOMIA MINEIRA, 12., 2006, Diamantina. Anais. Belo Horizonte: CEDEPLAR/UFMG, 2006. p. 01-23.

IBGE. Pesquisa Regiões de Influência das Cidades - informações de deslocamentos para serviços de saúde (notas técnicas). IBGE: Rio de Janeiro, 2020.

IBGE. Regiões de Influência das Cidades - 2007. IBGE: Rio de Janeiro, 2008.

JOHNSON, Steven. O mapa fantasma: como a luta de dois homens contra o cólera mudou o destino de nossas metrópoles. Rio de Janeiro: Zahar, 2008.

PEREIRA, A. Q. Espaço-tempo de confinamento no Oeste francês: estatísticas, mapas, impressões. Espaço e Economia: Revista brasileira de geografia econômica, [on line], 18, 2020, Acessado em 05 
de maio de 2020. Disponível em: http://journals.openedition.org/espacoeconomia/11962 https://doi.org/10.4000/espacoeconomia.11962

SANTOS, M.; SILVEIRA, M. L. O Brasil: território e sociedade no início do século XXI. Rio de Janeiro: Record, 2006.

SILVA, J. B.; MUNIZ, A. M. V. Pandemia do Coronavírus no Brasil: Impactos no Território Cearense. Espaço e Economia: Revista brasileira de geografia econômica, [on line], 17, 2020, Acessado em 06 de maio de 2020. Disponível em: http://journals.openedition.org/espacoeconomia/10501 https://doi.org/10.4000/espacoeconomia.10501

SIMÕES, R.; GUIMARÃES, C.; GODOY, N.; VELLOSO, T.; ARAÚJO, T.; GALINARI, R.; CHEIN, F. Rede urbana da oferta de serviços de saúde: uma análise espacial multivariada para Minas Gerais. In: SEMINÁRIO SOBRE ECONOMIA MINEIRA, 11., 2004, Diamantina. Anais. Belo Horizonte: Universidade Federal de Minas Gerais, 2004. p.1-32.

SOUZA, M.V.M.; FERREIRA JUNIOR, D.B. Rede urbana, interações espaciais e a geografia da saúde: análise da trajetória da Covid-19 no estado do Pará. Espaço e Economia: Revista brasileira de geografia econômica, [on line], 18, 2020, acessado em 02 de maio de 2020. Disponível em: http://journals.openedition.org/espacoeconomia/13146 https://doi.org/10.4000/espacoeconomia.13146

SPOSITO, M. E. B.; GUIMARÃES, R. B. Por que a circulação de pessoas tem peso na difusão da pandemia. São Paulo: Unesp, 26 mar. 2020. Disponível em:

<https://www2.unesp.br/portal\#!/noticia/35626/por-que-a-circulacao-de-pessoas-tem-peso-na-difusaoda-pandemia>. Acesso em 20 abr.2020. 